\title{
EVALUATION OF GENERATION SYSTEM RELIABILITY INDICES USING RBFNN METHOD
}

\author{
Ravindra M. Moharil ${ }^{1 *}$, Prakash S. Kulkarni ${ }^{2}$ \\ ${ }^{1}$ Professor, Yeshwantrao Chavan College of Engineering, Wanadongri, Hingna Road Nagpur, Maharashtra, India, Pin - 441110. \\ ${ }^{2}$ Associate Professor, Department of Electrical Engineering, Vishveshvarya National Institute of Technology, \\ Nagpur, Maharashtra, India. Pin-440011. \\ Corresponding Author Email: \{rmm_ycce_ep@yahoo.com\}
}

\begin{abstract}
Electrical power system is changing from utility centric to customer centric after introduction of Electricity Act 2003 in India and unbundling of power sector in rest of the world. After unbundling, customer satisfaction has prime importance. Customer expects power supply $24 \times 7$, which can be assured only after performing the reliability analysis of generation system. The purpose of this paper is to present Neural Network (NN) approach, which can overcome limitations of the conventional reliability evaluation method such as poor accuracy, complicated models, and large time for execution. This paper presents an organized approach for establishing the learning model with supervision using radial basis function neural network (RBFNN). This model is used for evaluation of various reliability indices used for generation planning. Markov process and basic probabilistic approach is used to develop the input- output training patterns for neural network. These patterns are normalized and presented to RBFNN. The validation of the proposed technique is confirmed by analyzing Roy Billinton Test System (RBTS) and IEEE-Reliability Test system (IEEE-RTS).
\end{abstract}

Keywords - Expected Energy Not Served (EENS), Forced outage rate (FOR), Loss of Load Expectation (LOLE), orthogonal least square (OLS), Radial Basis Function Neural Network (RBFNN).

\section{Introduction}

Electrical energy cannot be stored in large amount and hence it is necessary to balance the power generation and load While designing, planning and expansion the generation system to ensure availability of electric power to consumer reliability analysis is used [1]. Billinton and Allan in their paper expressed that, the load on the power system is not remains constant but varied continuously based on weather and time of day. Modern electric utility uses conventional generation sources like coal, hydro and nuclear and renewable energy sources like wind and solar with different capacity. Installed generators in the system may get failed due to technical problems and required to be taken out of service. Failure of generator and variation in load both are random in nature. Probabilistic approach is preferred to perform the reliability evaluation of generators [2]. Billinton and Tang in their paper mentioned that adequacy analysis of generation -

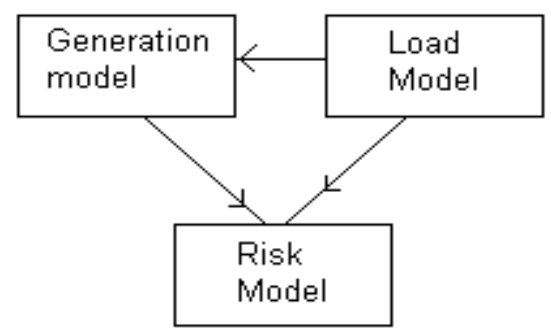

Fig. 1: Generator adequacy evaluation model transmission availability can be done using MonteCarlo simulation [3]. Initially the generator model is prepared for capacity usage using statistical data of failure of generator and load model is prepared based on daily and seasonal forecasting. These two models are then convoluted to obtain the risk model as shown in Fig. (1). Various reliability indices are defined for adequacy evaluation of generators. When the load is more than available generation then it is known as loss of load. Expected number of hours or days when loss of load occurs is defined as loss of load probability or expectation (LOLP or LOLE). The amount of energy not supplied due to non-availability of generation is known as expected energy not supplied (EENS). While performing this loss of load (LOL) evaluation requires all data related about generation status of different units and load data variation due to time and season.

Sivanandam et al. has described various engineering problem solutions using soft computing like neural network (NN) and genetic algorithm (GA), which learn from the experience like the nervous system of the human body [4]. Nima Amjady and Mehdi Ehsan in their paper developed reliability analysis based on Artificial Neural Network (ANN) [5]. Flynn Meadhbh et. al in their paper uses Lagrangian dual function for generation reliability evaluation [6]. RBFNN function was used by various authors for design of UPFC controller, economic load dispatch problem, reliability worth analysis [7-9]. Armando M. Leite da Silva in their paper uses group method data handling (GMDH) for 
composite generation and transmission system reliability analysis using polynomial function. Abdollah Kavousifard and Haidar Samet trained RBFNN using neuro-fuzzy logic to obtain reliability assessment. Monte Carlo simulation considering power market behaviour, learning vector quantization (LVQ), least square support vector machine classifier, multilabel $\mathrm{RBF}$ for reliability evaluation [12-15]. Hamid Reza Baghaee et. al in their paper shows ability of artificial neural network for non-linear mapping of renewable sources for probabilistic power flow approach. Alireza Heidari et. al presented cascade correlation neural network to develop cost model to conduct reliability worth analysis. Whei-Min Lin presented application of probabilistic insecurity index (PISI) using RBFNN for security operation considering voltage stability limit.

This paper presents, RBFNN method for design and simulation to obtain the reliability indices such as LOLE, EENS and EIR. The results obtained from RBFNN method are compared with probabilistic method. RBFNN gives simple architecture, good generalization, fast computing, and high solution accuracy.

\section{Proposed method}

While preparing the generator model, its availability and un-availability is obtained from historic data of similar type of generators. The forced outage rate (FOR) is obtained using formula (1).

$$
\begin{aligned}
& \text { FOR }=\text { Unavailability }=\frac{\sum \text { (downtime) }}{\sum(\text { downtime })+\sum(\text { uptime })} \\
& \text { Availability }=\frac{\sum_{\text {(uptime })}}{\sum(\text { downtime })+\sum \text { (uptime) }}
\end{aligned}
$$

Cumulative probability-based Capacity outage probability table (COPT) is obtained for multi-state units using capacity, state and probability of the generator using equation (3). When ' $n$ ' is equal to two, equation (3) is for two state model.

$$
P(X)=\sum_{i=1}^{n} p_{i} P^{\prime}\left(X-C_{i}\right)
$$

Daily peak load or hourly loads are used for convolution load model with generator model and obtain the risk of Loss of load expectation (LOLE)

using equation (4) for the specific time interval.

$$
\text { LOLE }=\sum_{i=1}^{n} P_{i}\left(C_{i}-L_{i}\right)
$$

Expected Energy not supplied (EENS), is obtained using equation (5) by taking product of power curtained, time and its probability.

$$
\text { EENS }=\sum_{j=1}^{m} \text { Energy_curtailed }_{j} \times P_{j}
$$

The relationship of EENS and total load is given by the energy index of reliability (EIR) as shown in equation (6),

$$
E I R=1-\frac{\text { EENS }}{\text { Total_Load }}
$$

Radial basis function (RBF) network can be used for approximating functions and recognizing patterns. It uses Gaussian Potential functions. The architecture of RBF network is as shown in Fig. 2. Input and output layers are interconnected through hidden layer. Hidden layer and input layer have hypothetical connection whereas output and hidden layer has weighted connection. Orthogonal least square (OLS) training algorithm is used for updation of weights in all the interconnections. The hidden layer consists of set of radial basis functions. All the RBF in the hidden layer nodes are usually of the same type. Thus, the hidden layer performs a fixed non-linear transformation with no adjustable parameters, and it maps the input space onto a new space. This new space input has linear combiner relationship with output with weights These parameters can be obtained using the OLS method [4].

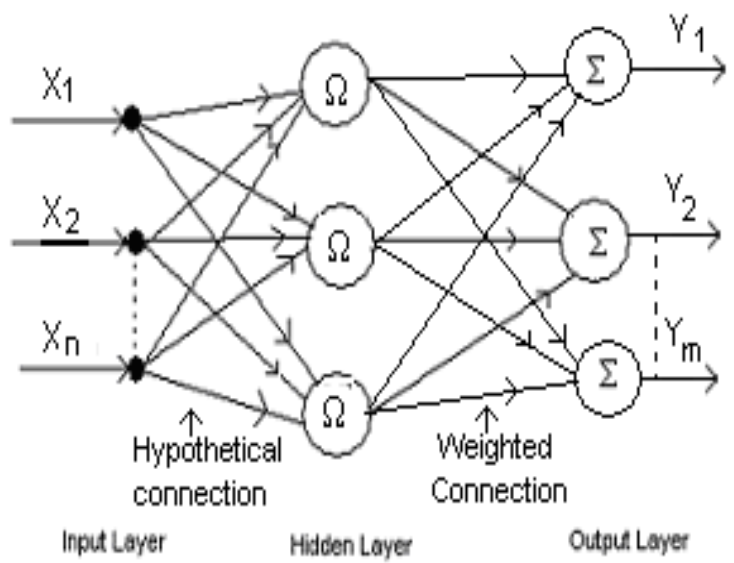

Fig. 2 Multi neuron RBFNN structure

\section{Design of RBFNN}

In case of RBFNN analysis, to obtain the solution of any problem is divided into two parts as design of RBFNN and training of RBFNN. The first step in designing is to identify the input and output. In second step RBF centers are identified and in last step weights are obtained between hidden and output layer. During training hidden center and their corresponding weights with output are identified. Proper identification of hidden center is important as linear relationship between hidden and output layer make it easy to obtain the adjustable weights 
W. Function newrb from MATLAB is used to add neurons in network as shown in equation (7) [4].

$$
[\text { net, } \mathrm{tr}]=\text { newrb }(\mathrm{P}, \mathrm{T}, \text { goal,spread,MN,DF })
$$

Equation (7) right hand side has input vectors(P), target vector(T), error goal(eg), spread, number of maximum neurons( $\mathrm{MN})$ and number of neurons for display (DS).

Equation (7) gives new radial basis network. Selection of spread constant decides the requirement of number of neurons which depends on fast changing and smoothing function. The updation in the network is done using function nnt2rb function of MATLAB as shown in equation (8). Right hand side of equation (8) represents input elements (PR), weight matrix $\left(\mathrm{W}_{1}\right.$ and $\left.\mathrm{W}_{2}\right)$, bias vectors $\left(B_{1}\right.$ and $\left.B_{2}\right)$. Left hand side of equation (8) represents the radial basis network.

$$
n e t=n n t 2 r b\left(P R, W_{1}, B_{1}, W_{2}, B_{2}\right)
$$

Function sim of MATLAB is used to simulates neural networks as shown in equation (9). It has network (net), network input P) snd network targets (T) as the input argument and its output is network output (Y), network error (E) and network performance (perf).

$$
\left[\mathrm{Y}, \mathrm{P}_{\mathrm{f}}, \mathrm{A}_{\mathrm{f}}, \mathrm{E}, \mathrm{perf}\right]=\operatorname{sim}(\text { net, } \mathrm{P}, \mathrm{T})
$$

\section{Test Results}

For the problems of reliability, the load demand in the training set is known a priori. In this paper RBFNN supervised network is used. Peak load on the system is used as input to the neural network and output contains LOLE, EENS and EIR. RBFNN approach for reliability analysis is tested on few sample system. The results obtained are then compared with conventional probabilistic method approach for reliability. The program for obtaining LOLE, EENS and EIR is developed using MATLAB 6.5 and the RBFNN approach is applied using MATLAB 6.5 neural network toolbox.

\subsection{Case 1}

The test system data is taken from Billinton (1994). Four units of generator with capacity of 10$40 \mathrm{MW}$ are used. Total generation capacity is 100 MW. Each unit has FOR of 0.08. Maximum load of the system is $70 \mathrm{MW}$. The reliability indices are calculated by considering a load duration curve for 100 days period. This curve is assumed to be a straight line from $100 \%$ to $60 \%$ load point. The same system is further studied by considering 40 MW generator in derated state. Thus $40 \mathrm{MW}$ unit has three states. First state with 0 MW capacity having a probability of 0.08 . Second state with 20 MW capacity having a probability of 0.06 . Third state of $40 \mathrm{MW}$ capacity with probability of 0.86 [1].

When the system is without derated state then 8 training patterns are generated by varying load in between $70 \mathrm{MW}$ to $100 \mathrm{MW}$. The RBFNN is tested with five test patterns and the accurate results are obtained without derated state at error goal $=0.02$ and spread constant $=0.6$. Four neurons are required in the hidden layer. The output results of RBFNN and probabilistic approach are compared in Table I.

When the derated state is considered then 8 training patterns are generated by varying load in between $70 \mathrm{MW}$ to $100 \mathrm{MW}$. The RBFNN is tested with five test patterns and the accurate results are obtained at error goal $=0.02$ and spread constant $=$ 1. The hidden layer requires two neurons. The output results of RBFNN and probabilistic approach are compared in Table II.

Table I- Comparison of RBFNN and Probabilistic approach results for case 1.

\begin{tabular}{|l|l|l|l|l|l|l|}
\hline \multirow{2}{*}{\begin{tabular}{l} 
Test $\begin{array}{l}\text { Load } \\
(\mathrm{MW})\end{array}$ \\
\cline { 2 - 7 }
\end{tabular}} & \multicolumn{2}{|c|}{ LOLE (days/yr.) } & \multicolumn{2}{c|}{ EENS (MW) } & \multicolumn{2}{c|}{ EIR } \\
\hline 71 & 3.6749 & 3.6749 & 52.7976 & 52.7975 & 0.9907 & 0.9907 \\
\hline 78 & 6.6277 & 6.6277 & 92.7021 & 92.7021 & 0.9851 & 0.9851 \\
\hline 86 & 9.3773 & 9.3773 & 160.5065 & 160.5066 & 0.9767 & 0.9767 \\
\hline 93 & 12.8961 & 12.8962 & 240.8921 & 240.8922 & 0.9676 & 0.9676 \\
\hline 96 & 14.5252 & 14.5252 & 281.9450 & 281.9450 & 0.9633 & 0.9633 \\
\hline
\end{tabular}

Table II- Comparison of RBFNN and Probabilistic approach results for case 1 (derated).

\begin{tabular}{|c|c|c|c|c|c|c|}
\hline \multirow{2}{*}{$\begin{array}{c}\text { Test } \\
\text { Lod } \\
(\mathrm{MW})\end{array}$} & \multicolumn{2}{|c|}{ LOLE (days/yr) } & \multicolumn{2}{c|}{ EENS (MW) } & \multicolumn{2}{c|}{ EIR } \\
\cline { 2 - 7 } & RBFNN & Probabilistic & RBFNN & Probabilistic & RBFNN & Probabilistic \\
\hline 71 & 4.1185 & 4.1185 & 58.3431 & 58.3432 & 0.9897 & 0.9897 \\
\hline 78 & 8.6343 & 8.6343 & 136.3818 & 136.3818 & 0.9798 & 0.9798 \\
\hline
\end{tabular}




\begin{tabular}{|l|l|l|l|l|l|l|}
\hline 86 & 10.3900 & 10.3900 & 176.3397 & 176.3396 & 0.9744 & 0.9744 \\
\hline 93 & 14.6661 & 14.6661 & 268.4696 & 268.4697 & 0.9639 & 0.9639 \\
\hline 96 & 16.5678 & 16.5678 & 315.8257 & 315.8257 & 0.9589 & 0.9589 \\
\hline
\end{tabular}

\subsection{Case 2}

The Roy Billinton Test System (RBTS) has the installed capacity is $240 \mathrm{MW}$ and the system maximum load is $185 \mathrm{MW}$. The load in a power system changes continuously. For RBTS the hourly and weekly load varies in terms of peak load of the system. Such 8736 variable load points are considered for LOLE in hours per year and 364 days are considered for calculating LOLE in days per year. The system voltage level is $230 \mathrm{kV}$ [19]. For neural network 23 inputoutput-training patterns are generated by varying load from $185 \mathrm{MW}$ to $240 \mathrm{MW}$. The five test patterns are used.

Table III- Comparison of RBFNN and Probabilistic approach results for case 2.

\begin{tabular}{|c|c|c|c|c|c|c|c|c|}
\hline \multirow{2}{*}{$\begin{array}{c}\text { Test } \\
\text { Load } \\
\text { (MW) }\end{array}$} & \multicolumn{2}{|c|}{ LOLE (hrs/yr) } & \multicolumn{2}{|c|}{ LOLE (days/yr) } & \multicolumn{2}{l|}{ EENS (MW) } & \multicolumn{2}{c|}{ EIR } \\
\cline { 2 - 10 } & RBFNN & Prob & RBFN & Prob & RBFNN & Prob & RBFN & Prob \\
\hline 191 & 1.7383 & 1.7384 & 0.2104 & 0.2104 & 10.8127 & 10.8127 & 1.0000 & 1.0000 \\
\hline 197 & 3.0504 & 3.0504 & 0.4206 & 0.4206 & 18.2060 & 18.2059 & 1.0000 & 1.0000 \\
\hline 203 & 4.6595 & 4.6595 & 0.5992 & 0.5992 & 30.0250 & 30.0250 & 1.0000 & 1.0000 \\
\hline 217 & 13.4449 & 13.4448 & 1.8429 & 1.8429 & 95.5411 & 95.5413 & 0.9999 & 0.9999 \\
\hline 234 & 43.4239 & 43.4239 & 5.6031 & 5.6031 & 348.2810 & 348.2810 & 0.9997 & 0.9997 \\
\hline
\end{tabular}

Table IV-Comparison of RBFNN and Probabilistic approach for case 2 with derating of 40 MW generator.

\begin{tabular}{|l|l|l|l|l|l|l|l|l|}
\hline \multirow{2}{*}{\begin{tabular}{l} 
Test $\begin{array}{l}\text { Load } \\
\text { (MW) }\end{array}$ \\
\cline { 2 - 9 }
\end{tabular}} & LBFNN & Prob & RBFNN & Prob & RBFNN & Prob & RBFNN & Prob \\
\hline 191 & 1.2266 & 1.2266 & 0.1534 & 0.1534 & 7.1386 & 7.1386 & 1.0000 & 1.0000 \\
\hline 197 & 2.2413 & 2.2413 & 0.3225 & 0.3225 & 12.3711 & 12.3711 & 1.0000 & 1.0000 \\
\hline 203 & 3.5414 & 3.5414 & 0.4733 & 0.4733 & 21.0059 & 21.0060 & 1.0000 & 1.0000 \\
\hline 217 & 10.8753 & 10.8753 & 1.5411 & 1.5411 & 71.9850 & 71.9849 & 0.9999 & 0.9999 \\
\hline 234 & 37.2867 & 37.2867 & 4.8993 & 4.8993 & 281.6666 & 281.6666 & 0.9998 & 0.9998 \\
\hline
\end{tabular}

Table V - Comparison of RBFNN and Probabilistic approach results for case 3

\begin{tabular}{|c|c|c|c|c|c|c|c|c|}
\hline \multirow{2}{*}{$\begin{array}{c}\text { Test } \\
\text { Load } \\
\text { (MW) }\end{array}$} & \multicolumn{2}{|c|}{ LOLE (hrs/yr) } & \multicolumn{2}{c|}{ LOLE (days/yr) } & \multicolumn{2}{c|}{ EENS (MW) } & \multicolumn{2}{c|}{ EIR } \\
\cline { 2 - 9 } & RBFNN & Prob & RBFNN & Prob & RBFNN & Prob & RBFNN & Prob \\
\hline 2975 & 11.6100 & 11.6100 & 1.64920 & 1.64920 & 1548.2825 & 1548.2856 & 0.9998 & 0.9998 \\
\hline 3125 & 27.1361 & 27.1361 & 3.71087 & 3.71087 & 3952.4974 & 3952.4902 & 0.9997 & 0.9997 \\
\hline 3275 & 57.5348 & 57.5349 & 7.52838 & 7.52838 & 9193.6156 & 9193.6191 & 0.9994 & 0.9994 \\
\hline 3325 & 71.7853 & 71.7853 & 9.26429 & 9.26428 & 11931.3433 & 11931.3510 & 0.9992 & 0.9992 \\
\hline 3400 & 102.1723 & 102.1723 & 13.3859 & 13.3859 & 17393.1105 & 17393.1105 & 0.9989 & 0.9989 \\
\hline
\end{tabular}

When the system is without derated state the accurate results are obtained at error goal = 0.0145 and spread constant $=0.800$. Four neurons are required in hidden layer. The output results of RBFNN and probabilistic approach are compared in Table III.

\subsection{Case 3}

The IEEE-Reliability Test System (IEEE-RTS) has 24 bus structure with 32 generators. The total generation capacity of system is $3405 \mathrm{MW}$ and peak load on the system is $2850 \mathrm{MW}[20]$. For
When the system is with derated state the accurate results are obtained at error goal = 0.0150 , spread constant $=0.8$. Four neurons are required in the hidden layer. The output results of RBFNN and probabilistic approach are compared in Table IV.

IEEE-RTS the hourly and weekly load varies in terms of peak load of the system. Such 8736 variable load points are considered for LOLE in hours per year and 364 days are considered for calculating LOLE in days per year. Total 25 inputoutput training patterns are used in the range 2850 
MW to $3400 \mathrm{MW}$. The RBFNN is tested with five test loads. For IEEE-RTS system the accurate results are obtained at error goal $=0.02$, spread constant $=1$. Four neurons are required in hidden layer. The output results of RBFNN and probabilistic approach are compared in Table $\mathrm{V}$.

Table VI - Requirement of No. of Neurons for different Case Studies

\begin{tabular}{|l|c|c|c|c|c|c|}
\hline & $\begin{array}{l}\text { No. of } \\
\text { outage } \\
\text { steps }\end{array}$ & $\begin{array}{l}\text { Training } \\
\text { patterns }\end{array}$ & Type of load & $\begin{array}{l}\text { Error } \\
\text { goal }\end{array}$ & $\begin{array}{l}\text { Spread } \\
\text { constant }\end{array}$ & $\begin{array}{l}\text { No. } \\
\text { Neurons }\end{array}$ \\
\hline $\begin{array}{l}\text { Case 1 with 4 units without } \\
\text { derating. }\end{array}$ & 11 & 08 & $\begin{array}{l}\text { Peak load with slope } \\
\text { over time duration }\end{array}$ & 0.0200 & 0.6 & 02 \\
\hline $\begin{array}{l}\text { Case 1 with 4 units with 40 MW } \\
\text { unit in derated condition. }\end{array}$ & 11 & 08 & $\begin{array}{c}\text { Peak load with slope } \\
\text { over time duration }\end{array}$ & 0.0200 & 1.0 & 03 \\
\hline $\begin{array}{l}\text { Case 2 with 11 units without } \\
\text { derating. }\end{array}$ & 49 & 23 & Hourly variation & 0.0145 & 0.8 & 04 \\
\hline $\begin{array}{l}\text { Case 2 with 11 units with 40 } \\
\text { MW unit in derated condition. }\end{array}$ & 49 & 23 & Hourly variation & 0.0150 & 0.8 & 04 \\
\hline $\begin{array}{l}\text { Case 3 with 32 units without } \\
\text { derating. }\end{array}$ & 3180 & 25 & Hourly variation & 0.0200 & 1.0 & 04 \\
\hline
\end{tabular}

\section{Conclusions}

In this paper an application of RBFNN for evaluation of generation system reliability indices is proposed. After studying case studies with daily maximum load and hourly variation in the load that number of RBF centers required are mainly depends on error goal and spread constant. RBFNN approach is confirmed by analyzing three test systems and the results obtained have been compared with probabilistic approach. Table VI represents thar error goal should be lowered down for a greater number of outage system. Number of neurons required varies from 2-4 depending on the outage steps and number of derated states involved. It can be concluded that with increase in outage steps percentage training patterns required reduces

\section{REFERENCES}

[1] Billinton Roy, Allan Ronald N. (1994), "Reliability Evaluation of Power Systems", Second Edition, Plenum Press, New York.

[2] Billinton Roy, Allan Ronald N. (2000), "Probabilistic Assessment of Power Systems", Proceedings of IEEE, vol.88, No.22, Feb., pp. 140-162.

[3] Billinton. Roy, Tang X. (2004), "Selected considerations in utilizing Monte Carlo simulation in quantitative reliability evaluation of composite power systems", Electric Power Systems Research, 69, pp.205-211.

[4] Sivanandam S. N., Sumathi S., Deepa S. N. (2006), "Introduction to Neural Networks using MATLAB 6.0”, Tata McGraw Hill Publishing Company Limited, New Delhi.

[5] Amjady Nima, Ehsan Mehdi (1999), "Evaluation of Power System Reliability by an artificial neural network", IEEE Transaction on for complex system to obtain accurate results. The performance of the RBFNN has been evaluated, through simulation studies, with respect to the architecture required, reliability and solution accuracy. The results obtained clearly indicate that the proposed RBFNN approach is a promising tool for evaluation of generation system reliability indices.

\section{ACKNOWLEDGEMENTS}

Authors are grateful to the authorities of the academic institutes Y.C.C.E. and V.N.I.T., Nagpur for granting permission to carry out the research work.

Power Systems, Vol. 14, No. 1, February, pp. 287-291.

[6] Flynn Meadhbh, Sheridan Paul, Dillon Joseph D., Mally Mark J. O. (2001), "Reliability and Reserve in Competitive Electricity Market Scheduling", IEEE Transaction on Power System, Vol. 16, No. 1, Feb., pp. 78-87.

[7] Dash P. K., Mishra S., Panda G.( 2000), “ A Radial Basis function Neural controller for UPFC", IEEE Transaction on Power System, Vol. 15, No. 4, Nov., pp. 1293-1299.

[8] Kulkarni P. S., Kothari A.G., Kothari D.P.(2002), “ Application of Radial Basis Function Neural Network for Economic Dispatch", IE(I) Journal EL, Vol. 83, Sept., pp. 81-86.

[9] Lin Whei Min, Zhan Tung Sheng, Yang Chin Der (2003), “ Distribution System Reliability worth Analysis with the customer cost model based on RBF Neural Network", IEEE Transaction on Power Delivery, Vol. 18, No. 3, July, pp. 1015-1021. 
[10] Armando M. Leite da Silva, Leonidas Chaves de Resende, Luiz Antônio da Fonseca Manso and Vladimiro Miranda, “ Composite Reliability Assessment Based on Monte Carlo Simulation and Artificial Neural Networks", IEEE Transactions on Power Systems, vol. 22, no.3, Aug. 2007, pp. 1202-1209.

[11]Abdollah Kavousifard, Haidar Samet, “ Consideration effect of uncertainty in power system reliability indices using radial basis function network and fuzzy logic theory", Neurocomputing, Vol. 74, 2011, pp. 3420-3427.

[12] H. Haroonabadi, M.-R. Haghifam, " Generation reliability assessment in power markets using Monte Carlo simulation and soft computing", Applied Soft Computing, Vol. 11, 2011 pp. 5292-5298.

[13]Xiaochuan Luo, Chanan Singh, Alton D. Patton, "Power system reliability evaluation using learning vector quantization and Monte Carlo simulation", Electric Power System and Research, 66 (2003), pp. 163-169.

[14] Naran M. Pindoriya, Panida Jirutitijaroen, Dipti Srinivasan and Chanan Singh, "Composite Reliability Evaluation Using Monte Carlo Simulation and Least Squares Support Vector Classifier", IEEE Transactions on Power Systems, Vol. 26, No. 4, Nov. 2011, pp. 2483 2490.

[15]Dogan Urgun, Chanan Singh, Vijay Vittal, “ Importance Sampling Using Multilabel adial Basis Classification for Composite Power System Reliability Evaluation”, IEEE Systems
Journal, Vol. 14, No. 2, June 2020, pp.27912800.

[16] Hamid Reza Baghaee, Mojtaba Mirsalim, G.B. Gharehpetian, H.A. Talebi, " Application of RBF neural networks and unscented transformation in probabilistic power-flow of microgrids including correlated wind/PV units and plug-in hybrid electric vehicles", Simulation Modelling Practice and Theory, Vol.72,2017, pp. 51-68.

[17] Alireza Heidari, Vassilios G. Agelidis, Josep Pou, Jamshid Aghaei, Amer M.Y.M Ghias, "Reliability Worth Analysis of Distribution Systems using Cascade Correlation Neural Networks", IEEE Transactions of Power Systems, In press (DOI: 10.1109/TPWRS.2017.2705185).

[18] Whei-Min Lin, Tung-Sheng Zhan, and ChinDer Yang, "Distribution System Reliability Worth Analysis With the Customer Cost Model Based of RBF Neural Network", IEEE Transactions on Power Delivery, Vol. 18, No. 3, July 2009, pp. 1015-1021.

[19] Billinton R, Kumar S., Chowdhury N., Chu K., Debnath K.( 1989) , “ A Reliability Test System for Educational Purposes - Basic Data”, IEEE Transaction on Power Systems, Vol. 4, No.3, Aug., pp.1238-1244.

[20] Reliability Test System task force (1999), "The IEEE Reliability Test System-1996”, IEEE Transaction on Power System, vol. 14, No. 3, Aug., pp.1010-1020. 